\title{
INNOVATIVE ESTEEM: ANTECEDENTS AND RELATIONSHIP WITH JOB PERFORMANCE
}

\author{
Ch. Mahmood Anwar ${ }^{1}$
}

1 Universiti Tunku Abdul Rahman, Faculty of Business and Finance, Malaysia, ORCID: 0000-0002-0526-2232, Mahmood.Anwar@scholarsindex.com.

\begin{abstract}
This study aims to present and validate a new psychological construct, i.e. innovativenessbased self-esteem or shortly "innovative esteem" which reflects that innovative individuals evaluate their innovative capabilities to determine their significance, successfulness, and worthiness in organizations. Innovative esteem reflects attributes and capacities manifested by individual's innovativeness specific feelings and evaluations about self. Standard procedures were followed to test construct and predictive validity for the new construct. Testing 546 paired responses from subjects working in hi-tech and $R \& D$ sectors, this study empirically identified that personal innovativeness, organization-based self-esteem, learning goal orientation, and job autonomy significantly contribute to innovative esteem in organizational setting. Test of theory of interaction revealed that learning goal orientation and job autonomy interact with each other to determine innovative esteem. In addition, this research correlated innovative esteem with employee job performance by considering it as independent index. Innovative esteem is found to be significantly and positively correlated to employee job performance. The study further applied regression analysis to strengthen the finding, and found that innovative esteem significantly predicted employee job performance in time lagged setting. To establish evidence of stability of innovative esteem over time, data were collected again after one year. The test-retest reliability correlation provided the evidence of stability of innovative esteem over time. Present study proposed that innovative works can best be performed by employees high in innovative esteem which could be further confirmed empirically. It is suggested that organizations can outperform if managers consider innovative esteem of employees along with other dispositional factors. It is further suggested that significance of innovative esteem should be explored further in personality psychology and organizational behaviour.
\end{abstract}

Keywords: Innovative esteem, personal innovativeness, self-esteem, self-concept, personality.

JEL Classification: C91, D23.

APA Style Citation: Anwar, C. M. (2020). Innovative Esteem: Antecedents and Relationship with Job Performance. E\&M Economics and Management, 23(4), 137-151. https://doi. org/10.15240/tul/001/2020-4-009

\section{Introduction}

Nowadays when businesses are facing intense rivalries, it is worthwhile for business organizations to recruit and retain workforce by adopting successful strategies to gain or sustain competitive advantage. Literature indicates that many factors (e.g., economic, financial, legal, structural, technical, procedural, and social) play an important role in determining organizational success (Pourhanifeh \& Mazdeh,
2016). Moreover, literature also highlights the importance of workforce which is considered as an essential element for organizations to outperform. Riaz et al. (2018) mentioned that currently organizations are putting more efforts to explore employees' innovative behaviour in order to obtain and sustain edge over competitors. Farid et al. (2017) highlighted that majority of the studies investigating innovative behaviour of employees were conducted at 
organizational level. They realized the need to conduct studies exploring innovativeness of employees at individual level.

Literature shows that only a few studies reported the relationship between individual innovativeness and self-concept. Self-concept has been studied by sociologists, personality and organizational psychologists, and educational researchers for more than a century (Onetti et al., 2019). Hitherto, the popularity of self-concept has been increased among personality psychologists and organizational researchers because its impact on human behaviour, cognition, and affect is pervasive (Onetti et al., 2019). It is evident that selfesteem, being a component of self-concept, plays an important role to motivate individuals to become innovative. Previously, Keller (2012) found self-esteem as a noteworthy determinant of individual's innovative outcome, whilst Maden and Koker (2013) reported that self-esteem significantly predicted consumer innovativeness. Noticeably, literature sheds a little light on the relationship between personal innovativeness and self-esteem. In addition, studies exploring mechanism behind the positive and significant association between personal innovativeness and self-esteem are also rare.

The remarkable words of wisdom by White (Neil, 2015, p. 99) "If a problem is not biological in origin, then it will almost always be traceable to poor self-esteem", urged researcher of this study to investigate personal innovativeness of employees by linking it to self-esteem. Previous literature indicates that only a few studies reported the association between individual innovativeness and selfesteem. Applying knowledge void method to derive the research problem and formulate the management question, the researcher observed that Goldsmith and Matherly (1987) tested the associations between Kirton's adaption-innovation inventory (KAl), and 12 items from adjective check list (ACL) with famous Rosenberg self-esteem scale (RSS). They found that innovative people are more likely to reflect high self-esteem but they did not endeavour to answer the question "why innovative people reflect high self-esteem?"

These studies, however, paved the way for further research. In addition, to the best of researcher's knowledge, no prior study construed personal innovativeness of employees within self-concept paradigm and linked it to self-esteem in order to investigate self-esteem that is specific to personal innovativeness. This study proposes that exploring personal innovativeness within self-concept paradigm could enhance our understanding on how innovative employees evaluate themselves and how this positive evaluation enhances individuals' performance outcomes. Therefore, by integrating literature on personal innovativeness and self-esteem, the researcher proposed a new psychological construct, i.e. innovativeness-based selfesteem or shortly "innovative esteem" which reflects individual's self-evaluations regarding his personal innovative capabilities. This research believes that innovative esteem may be responsible for the finding that innovative people are more likely to reflect high selfesteem.

The contribution of this study to the literature of innovativeness and self-esteem is significant. First, it introduces a psychological construct "innovative esteem" which may be an important construct in a work setting. Second, construct validity and predictive validity for new construct are established. Third, interactionist perspective for new construct is tested. Fourth, the scale development for innovative esteem is discussed. Fifth, this study extends Goldsmith and Matherlys' (1987) conceptual framework towards a new direction. Sixth, the study may start a new debate in the arena of innovation and personality research.

\section{Literature Review}

\subsection{Concept of Innovative Esteem}

Literature of innovation defined it broadly in product, process, system, technological, and administrative contexts. Individual innovation can be abstracted in several ways. Researchers operationalized this concept in terms of personal characteristics, outcomes, and behaviours. For instance, literature considered individual innovation to be personality-based (Hurt et al., 1977; Kerr et al., 2018). It is obvious that source of all innovation is human being, ergo, this study preferred to look into individual's innovativeness. Leavitt and Walton (1975, p. 549) delineated individual's innovativeness as "trait reflecting a person who welcomes new experiences and works in his own meaningful ways to experience different and novel stimuli", whereas Rogers (2003, p. 22) defined it as "the 
extent to which a person or unit of adoption is relatively earlier than other subjects of his circle".

According to Rosenberg (1965, p. 16), self-esteem reflects extent to which individuals feel pride in themselves, their capabilities and worthiness. Similarly, Coopersmith (1967, p. 4) defined it as "degree to which person believes himself to be successful, capable, significant, and worthy". Being an evaluative aspect of selfconcept (Kerr et al., 2018), self-esteem is an attitude of approval and indicates individual's beliefs about his skills, abilities, social relations, and other outcomes. Hence, considering innovativeness as a trait, this study infers that an individual may evaluate himself for being innovative in organizational settings.

Based on above definitions, Anwar et al. (2020) defined innovative esteem as "extent to which individuals feel pride and worthiness in their incremental and/or radical innovative capabilities". It is important to note that pride is mentioned with a positive connotation in this definition. Anwar et al. (2020) mentioned that innovative esteem should be confined within self-concept paradigm and is a unique construct because it reflects attributes and capacities manifested by individual's innovativeness specific feelings and evaluations about self.

Next section of this study focuses on the question: "Is innovative esteem a valid psychological construct within a nomological framework?" A new construct should be able to demonstrate theoretical construct validity because it is very difficult to describe effects of measurement errors on theoretical relationships among constructs if construct is not valid (Mohajan, 2017).

It is also suggested by personality psychologists that antecedents to a personality related construct should satisfy theory of interactionism (Kakkar et al., 2016). Mosley and Laborde (2016) mentioned that the theory of interactionism suggests that traits and situations interact together to affect behaviour, and neither dimension alone can be considered as the cause of behaviour.

Mohajan (2017) mentioned that test of predictive validity is also required for new constructs because this test predicts some form of behaviour. Predictive validity is a criteria-related validity which refers to operationalization's ability to predict something it should theoretically be able to predict.
Predictive validity uses the data tapped for a new measure to predict performance, where performance acts as a criterion (Trochim, 2016). Following similar approach, present study develops a nomological network to test theoretical/nomological construct validity, along with testing the theory of interactionism, and predictive validity for innovative esteem. In addition, the stability of innovative esteem will also be tested.

\subsection{Development of Nomological Network}

The initial nomological network specific to innovativeness has been developed by considering it as function of traits and work environment (Bateman \& Grant, 1999). Mathematically, innovativeness $=f$ (traits \& work environment), thus individual dispositional characteristics and work characteristics are explored concurrently. Present study develops a nomological network resulting in a set of hypotheses directing efforts to validate the innovative esteem and its measurement. From the previous literature, three personal and one contextual construct are selected as antecedents (nomologicals) to innovative esteem in order to limit the research framework of this study and to satisfy nomological network development directions provided by Cronbach and Meehl (1955), and Kakkar et al. (2016). The selected personal factors are: organizationbased self-esteem, personal innovativeness, and learning goal orientation. It is fathomable that organization-based self-esteem, and personal innovativeness are correlates of innovative esteem. However, learning goal orientation is considered to be a predictor of employee innovative behaviour as suggested by VandeWalle (1997). While the contextual factor is job autonomy which is regarded as work characteristic influences employees to involve in innovative behaviour (Hornung \& Rousseau, 2007; Sipe, 2018).

Learning goal orientation is selected as a nomological because literature linked it with self-concept and self-esteem (Button et al., 1996; Dweck \& Leggett, 1988). Dweck and Leggett (1988) mentioned that it is not only related to self-esteem but is a distinct construct and may add value to understand behaviour of people. Kunst et al. (2018) mentioned that learning goal orientation signifies intention of individuals to develop competencies, and 
acquire new knowledge and skills. Individuals high in learning goal orientation continuously explore and try new ways of work to ameliorate their knowledge and skills. Interestingly, Zhang et al. (2018) argued that learning goal orientation regulates individual's attention and endeavours in workplace which leads to the development of innovative solutions to challenging work-related problems. Nevertheless, goal orientation theory (see Nicholls \& Miller, 1983) suggests that individuals have different tendencies to evaluate their competencies. These individual differences are reflected in goal orientations.

Job autonomy is selected because research shows that autonomy orientation positively and significantly relates to self-esteem (Krause et al., 2019) and is important to augment the job performance of employees. In addition, selfdetermination theory (SDT) proposed by Deci and Ryan (2000) argues that people have innate psychological needs (e.g., relatedness, competence, autonomy) and if these needs are met, people can perform better and strengthen their skills optimally. This could enhance personal growth, vitality, wellbeing of employees, and ultimately, lead to high self-esteem. Based on these concepts, present research anticipates that job autonomy of employees could be a significant contributor to innovative esteem.

\section{Self-esteem and Personal Innovativeness}

Pagaduan-Apostol (2017) cites that development of individual's personality and competences is highly dependent on positive self-esteem. Previous literature shows significant positive association between innovativeness and self-esteem. For instance, Goldsmith and Matherly (1987) correlated Kirton's adaption-innovation inventory with Rosenberg self-esteem scale and found that innovative people are more likely to reflect high self-esteem. Likewise, Sternberg and O'Hara (1998) characterized the people involved in creative decision making on the basis of their high and low self-esteem. Similarly, Mason (2001) mentioned that employees high on selfesteem scale show more readiness to accept new and challenging assignments, are assertive and innovative as compared to employees with low self-esteem. Similar findings have been reported by Keller (2012), and Maden and Koker (2013).

Maslow considered "self-esteem" as an important factor to describe the satisfaction of esteem needs (Di Domenico \& Fournier, 2017). Revising Maslow's theory of motivation, KoltkoRivera (2006) found that social recognition of individuals' accomplishments significantly raised their self-esteem level. The researcher believes that high level of self-esteem is essential to achieve high work performance. Likewise, Lin and Filieri (2015) noted that individuals' motivation to achieve innovative outcomes boost their self-esteem level over time. Literature confirms that Maslow's theory of motivation encourages creativity and innovativeness (Madsen \& Wilson, 2012). Present research deems that individuals who get social respect and attention due to their innovative capabilities are more likely to internalize the value of innovation. They consider innovativeness as their major driving force to achieve higher level of performance. When a person realizes his innovative capabilities, he/she develops a strong belief that his/her innovative capabilities will increase his/her level of performance.

Literature suggests that individuals may evaluate themselves in different contexts/ domains of life like social-self, moral-self, work-self, athletic-self, academic-self, nonacademic-self etc. The most relevant context to present study, in which self-esteem arises, is organizational context. Therefore, organizationbased self-esteem (OBSE), which is a domain specific self-esteem (Gardner \& Pierce, 2015), could be linked to the innovative esteem. Literature shows that scholars have rigorously developed global self-esteem concept over the past couple of decades, however, domain specific self-esteem is underdeveloped. Therefore, much less is known about how domain specific self-esteem functions in general and in the context of creativity and innovation (Harris et al., 2018).

Pierce et al. (1989, p. 625) delineated organization-based self-esteem as "the extent to which a person believes himself to be significant, meaningful, capable, and valuable within their employing corporation". Gardner and Pierce (2015) mentioned that Pierce et al. (1989) advanced definition of OBSE by adding an organizational context into Coopersmith's (1967) definition of self-esteem. It has been established that self-esteem is a significant predictor of innovativeness, thus, organizationbased self-esteem may predict employees' innovative esteem in a workplace. Therefore, the following hypotheses are proposed: 
H1: Personal innovativeness will positively predict innovative esteem.

H2: Organization based self-esteem will positively predict innovative esteem.

\section{Learning Goal Orientation}

VandeWalle (1993) suggested that goal orientation should be explored in management and organizational research. Goal orientation theory postulates it as an internal motivation process that reflects individual differences in work-related and achievement-related behaviours. Researchers not only studied goal orientation in the context of learning and performance (VandeWalle, 1997) but also linked it to self-regulatory behaviours (Ford, 1996).

Learning goal orientation has been linked with self-concept and self-esteem in literature (Button et al., 1996; Dweck \& Leggett, 1988). Dweck and Leggett (1988) suggested that learning goal may be an imperative element of self-concept. Their instrumental conceptual framework considers learning goal orientation as a dispositional and enduring behavioural characteristic of people. They also reported that learning goal-oriented people reflect high selfesteem. Similarly, Button et al. (1996) tested relationship between learning goal orientation and implied concepts including self-esteem and found a positive correlation. On the other hand, VandeWalle (1997) mentioned learning goal as an individual's desire to learn new skills, augmenting competence, and new situations mastery.

Zhang et al. (2018) argued that learning goal orientation regulates individual's attention and endeavours in workplace which leads to the development of innovative solutions to challenging work-related problems. Kunst et al. (2018) explained that learning goal orientation signifies intention of individuals to develop competencies, and motivates them to acquire new knowledge and skills. Individuals high in learning goal orientation continuously explore and try new ways of working to ameliorate their knowledge and skills. Relatedly, Porath and Bateman (2006) determined that people high in learning goal orientation are likely to be engaged in proactive behaviour, implementing changes, and in-role innovation. While Munton and West (1995) found that role innovation is predicted by self-esteem. Based on these theoretical arguments, the following hypothesis is proposed:
H3: Learning goal orientation will positively predict innovative esteem.

\section{Job Autonomy}

Kerr et al. (2018) mentioned that work experiences of employees affect their selfevaluation. Being an evaluative aspect of selfconcept, self-esteem is influenced by work conditions or characteristics like job autonomy (Krause et al., 2019) which is considered as major shaper of employees' attitudes, behaviours, and motivations (Hornung \& Rousseau, 2007). Amabile et al. (1996) indicated that contextual factors are psychologically assessed by employees in organizations and these factors determine the degree of novel and nifty ideas generation. Krause et al. (2019) reported that degree of freedom an employee has over his work influences his self-esteem. In addition, Hornung and Rousseau (2007) theorized that job autonomy stimulates creation of self-starting and proactive behaviours. Literature reflects that job autonomy predicts personal innovativeness, innovative behaviour, and innovation (Sipe, 2018). Similarly, Lin and Filieri (2015) suggested that innovative people are more likely to reflect high self-esteem. Hence, these views are related to job autonomy and promote individuals to show augmented confidence to accept wider job roles and to behave in innovative and novel ways.

Present study holds that self-determination theory provides valuable support to select job autonomy as an antecedent to innovative esteem because self-determination theory has been widely utilized by contemporary organizational researchers to explain employee creativity and innovativeness (Sipe, 2018). For instance, applying selfdetermination theory, Sipe (2018) assessed how do senior management enable innovative organizational capabilities. $\mathrm{He}$ applied psychological needs of autonomy and relatedness to advance his context specific model of organizational capacities for innovation. Recently, Krause et al. (2019) conducted a research to analyse individuals' motivation and well-being in education sector by applying self-determination theory and found that psychological need of autonomy and competence is positively related to selfesteem. These theoretical propositions about job autonomy, innovativeness and self-esteem lead to the position that job autonomy may 
influence innovative esteem of employees in organizational settings.

H4: Job autonomy will positively predict innovative esteem.

\subsection{Interactionist View}

Interactionist perspective advocates that individuals being change agents are influenced by contextual factors (Mosley \& Laborde, 2016). For instance, contextual factors influence individual decision making, individual innovation, entrepreneurial attitudes etc. This view is rooted in interactional psychology and emphasizes the significance of interaction between person and situation (McCormick et al., 2019). This leads to the assertion that personal and contextual factors interact with each other to support innovativeness within individuals in organizational settings (Ford, 1996; McCormick et al., 2019; Oldham \& Cumings, 1996).

Noordzij et al. (2013) stated that goal orientation is a trait and an individual preference that may be affected by situational features. As indicated in nomonet development section of this study, one selected personal factor was learning goal orientation (VandeWalle, 1997), while contextual factor was job autonomy (Hornung \& Rousseau, 2007). Following theory of interactionism, the interaction of stable dispositions with contextual cues will play a crucial role in governing innovative behaviour. To test the theory of interactionism in the context of this study, whether interaction of both factors impacts the innovative esteem, the following hypothesis is proposed:

H5: Job autonomy will moderate the relationship between learning goal orientation and innovative esteem.

\subsection{Predictive Validity}

Validity theory suggests that performance of an operationalization must be checked against some criterion to establish predictive validity for new traits. Predictive validity uses the data tapped for a new measure to predict performance (or other independent index such as psycho-physiological functioning or employee behaviour), where performance acts as a criterion (Trochim, 2016). Following the analogous approach, predictive validity for innovative esteem will be established by correlating it with employees' job performance.

Literature mentions job performance as controllable activities and behaviours of persons that contribute to organizational goals. Job performance theories insinuate it as function of motivation and ability (e.g., Judge et al., 1998). Maslow's theory of motivation suggests self-esteem as a strong motivator of human behaviour (Maslow, 1943), and innovativeness as the individual's ability to launch new ideas through out of box thinking and is an individual characteristic (Rogers, 2003), therefore, innovative esteem could be thought as function of job performance.

Present study also established the position that innovative esteem should be confined within self-concept paradigm. Self-concept is an important antecedent to job related behaviours, job satisfaction, work behaviours and job performance. More specifically, Judge and Bono (2001) found a significant positive association between self-esteem, job satisfaction and job performance. Based on these theoretical arguments the following hypothesis is proposed:

H6: Innovative esteem will positively predict employee innovative job performance.

\section{Research Methodology}

\subsection{Sample and Procedure}

Surveys were personally administered to 550 full time permanent employees (technologists, engineers, scientific researchers) working in 15 hi-tech and R\&D organizations of Pakistan at Time 1 and second sample was taken from the same employees at Time 2 (after 12 months). The job nature of employees was creative/ innovative. Time lagged design was preferred because this study intends to establish an evidence of stability of innovative esteem among subjects over time in work settings. Following the standard cultural and ethical protocols of research, 550 standard surveys were personally distributed among study subjects after briefing them about the objectives of the research and requested them to participate in this research voluntarily and with their consent. They were further told that there is no risk involved if they participate in his study. Because English is the official language of Pakistan, translation of the surveys into national language was not needed.

Out of 550 standard paired surveys, 326 were received back (response rate $=59.27 \%$ ). After checking all surveys for errors and accuracy, it was found that $22\left(t_{1}\right)$ questionnaires were not usable due to missing values and overwriting. Hence, 304 (93.25\% of received responses) 
responses were selected for final analyses. Because this study intended to establish evidence of stability of innovative esteem, the study subjects and their supervisors were contacted again to provide responses for innovative esteem and job performance after one year. Unfortunately, 43 subjects were not available due to job rotations, international trainings, and other inevitable reasons. Hence, paired responses from 261 subjects were received back. After checking the responses, it was determined that 19 responses were not usable due to errors. Therefore, 242 paired responses were available for final analyses at Time $2\left(t_{2}\right)$.

To get supervisory data for job performance, the respective supervisors were identified (employees self-identified their supervisors), contacted, and requested to provide performance data for their supervisees. It was assured that their confidentiality will be maintained and no risk is involved if they participate in this study. Employee code and position were included on both employee and supervisor rated questionnaires to match and track the employees.

Most of the subjects were aged between $31-40$ years. $78 \%$ respondents were male and $22 \%$ were female. Most of the respondents had earned their Bachelor's degrees in engineering/ technology, whereas most of the employees were working in their respective organizations from 11-20 years. The descriptive statics of the sample are shown in Tab. 1.

General linear regression model assumes that all regressors should be independent to each other. Simply, there should be no autocorrelation among the disturbances of two or more regressors. The chances of dependence among regressors are less with the random sampling and increase with convenience sampling in cross sectional data or data collected from multiple organizations. However, this problem of autocorrelation is sterner in time series data, especially when the time interval between data collection points is short (Anwar, 2015). To test the independence of our regression model, the study estimated the Durbin-Watson (DW) value. The results were validated by computing Intraclass Correlation Coefficient (ICC). Researchers suggest that the DW score far away from 2 and near to 0 indicates the problem with independence. Statisticians recommend that DW coefficient should lie in the range of 1.5 to 2.5 . ADW score of 1.71 was calculated for regression model which showed that the variables were independent and had no significant evidence of autocorrelation. The results were cross validated by calculating ICC value for model. ICC method constructs a null linear model to estimate reliability coefficient. In this study, a two-way random effect model was applied with consistency type mix at 0.05 significance level to determine IC coefficient against the value zero (0). For this study model the average scores of independent variables were highly reliable, generating the ICC value of 0.81 (interval 0.76 to 0.89 with $95 \%$ confidence). The significant ICC value showed significant data independence.

\subsection{Measures}

Organization based self-esteem was measured with 10 items of the organization-based selfesteem Scale (OBSE) developed by Pierce et al. (1989). 5-point Likert format was used to tap responses $(1=$ strongly disagree, $5=$ strongly agree). For present study the scale reliability was 0.81 .

Personal innovativeness was measured with 20 items of the individual innovativeness scale (IIS) developed by Hurt et al. (1977). 5 -point Likert format was used to tap responses ( 1 = strongly disagree, $5=$ strongly agree). For present study the scale reliability was 0.85 .

Learning goal orientation was assessed using 5 items subscale of goal orientation scale (GOS) developed by VandeWalle (1997). Responses were tapped on 6-point forced Likert scale ( 1 = strongly disagree, $6=$ strongly agree). For current study the reliability was 0.92 .

The job autonomy was tapped using 3 items subscale of job diagnostic survey (JDS) subscale developed by Idaszak and Drasgow (1987). The subscale assessed job autonomy on a 7-point Likert format (1 = very inaccurate, 7 = very accurate). For current study the reliability was 0.79 .

Employee job performance was measured with 3 items performance scale developed by Heilman et al. (1992). 5-point Likert format was used to tap responses from supervisors about their subordinates ( 1 = strongly disagree, $5=$ strongly agree). For present study the scale reliability for Time $1\left(t_{1}\right)$ was 0.80 and for Time $2\left(t_{2}\right)$ was 0.82 .

Innovative esteem scale was developed by carefully examining the literature on personal innovativeness (e.g. Leavitt \& Walton, 
1975; Rogers, 2003) and self-esteem (e.g. Rosenberg, 1965; Coopersmith, 1967). An expert panel comprising 43 social/management sciences experts was formed to validate items pool and to check the items for translation (face and content) validity (40 items were created initially and 30 items were approved finally). Items were designed in the light of definition of innovative esteem, i.e. the extent to which individuals feel pride and worthiness in their innovative capabilities. Following deductive scale development technique, theoretical definition of the construct was developed first which was then used as a guide to generate domain specific items. The study followed the deductive scale construction framework to develop the scale as proposed by Hinkin et al. (1997).

Initial questionnaire was administered to 43 panellists. After checking the accuracy of data, exploratory factor analysis technique was applied and items were reduced to 9 (communalities after extraction ranged from 0.653 to 0.880 ). The second questionnaire was administered to 250 individuals working in hi-tech and R\&D sectors. After checking data for errors and omissions, the responses were again exploratory factor analysed (see Appendix: Tab. 1A) and items were reduced to 4 (communalities after extraction ranged from 0.597 to 0.915 , Kaiser-Meyer-Olkin (KMO) statistic for the data was 0.70 and Bartlett's Test of Sphericity statistic was $213.25(d f=28$, $p<0.001$ ). Components were retained by following the Kaiser criterion, i.e. items with eigenvalues greater than one. The four items solution explained $68.74 \%$ of total variance. The responses were tapped for hypothesis testing on 7-point Likert response format $(1=$ strongly disagree, $7=$ strongly agree). The title of new scale is Anwar's Innovative esteem Scale (AIS).

The scale alpha reliability for Time $1\left(t_{1}\right)$ was 0.87 and for Time $2\left(t_{2}\right)$ was 0.85 . The test-retest reliability was 0.95 , which is an evidence of stability of innovative esteem within study subjects over time because theoretically test-retest assumes that there is no significant change in the construct being quantified between two points of time. Discriminant validity was assessed by correlating innovative esteem with neuroticism because neuroticism is not similar to innovative esteem. Neuroticism was measured with 2 items taken from Ten Items Personality Inventory (TIPI) developed by Gosling et al. (2003). 5-point Likert format was used to tap responses $(1=$ strongly disagree, 5 = strongly agree). Items include "I see myself as anxious, easily upset" and "I see myself as calm, emotionally stable (R)". Gosling et al. (2003) reported that reliability coefficient for the scale was 0.70 . For current study the reliability was 0.72 . The significant correlation between personal innovativeness and innovative esteem scales $(r=0.47$; $p<0.01$ ), and organization based self-esteem and innovative esteem scales $(r=0.62$; $p<0.01$ ) provides the evidence of convergent validity, whereas negative correlation between neuroticism and innovative esteem $(r=-0.51$; $p<0.01$ ) provides the evidence of discriminant validity. The average variance extracted (AVE) for the construct was 0.72 (higher than 0.50 ) and composite reliability (CR) was 0.91 (greater than 0.70 ); this also provides the evidence of convergent validity. Discriminate validity was also established by comparing the square root of the average variance extracted (SQAVE) of innovative esteem to the correlation between the neuroticism and innovative esteem. To establish evidence of discriminant validity, the square root of average variance extracted should be much larger than the correlation value. In the case of present study, the square root of the average variance extracted was 0.85 , whereas the correlation between neuroticism and innovative esteem was -0.51 . The square root of average variance extracted was much larger than the correlation value. This provides the evidence of discriminant validity for innovative esteem.

This study included control variables like age, gender, education, and tenure into the regression model because researchers believe that these variables may confound the relationship between independent variables and innovativeness/creativity related dependent variable(s) (e.g. Riaz et al., 2018).

\section{Results}

The correlation between study variables can be seen in Tab. 1. The bivariate relationships shown in the correlation matrix indicate interim support to $H 1, H 2, H 3, H 4$ and $H 6$. To test $H 1, H 2, H 3$ and $H 4$ hierarchical regression analysis was performed. In first step, control variables (age, gender, education, tenure) and innovative esteem were entered. In step 2, personal innovativeness, organization-based 
self-esteem, learning goal orientation, and job autonomy were entered into the model. The results of the regression analysis presented in Tab. 2 indicate that personal innovativeness $(\beta=0.19, p<0.001)$, organization based self-esteem ( $\beta=0.41, p<0.001$ ), learning goal orientation $(\beta=0.35, p<0.001)$, and job autonomy $(\beta=0.24, p<0.001)$ are significant predictors of innovative esteem, hence, the findings provided well support to $H 1, H 2, H 3$ and $\mathrm{H} 4$. Besides that, total estimated variance explained by the model was $41 \%$, with the block of personal innovativeness, organization-based self-esteem, learning goal orientation, and job autonomy explaining $39 \%$ of the variance.

To test $H 5$, interaction term was added into regression analysis to explore interactional effects. The model without interaction term

\section{Tab. 1: Descriptive statistics, correlations and reliabilities of key study variables ${ }^{a}$}

\begin{tabular}{l|c|c|c|c|c|c|c|c|c|c|c|c}
\multicolumn{1}{c|}{ Variables } & $\mathbf{M}$ & SD & $\mathbf{1}$ & $\mathbf{2}$ & $\mathbf{3}$ & $\mathbf{4}$ & $\mathbf{5}$ & $\mathbf{6}$ & $\mathbf{7}$ & $\mathbf{8}$ & $\mathbf{9}$ & $\mathbf{1 0}$ \\
\hline Age & 2.70 & 0.91 & & & & & & & & & & \\
\hline Education & 2.81 & 0.63 & 0.01 & & & & & & & & & \\
\hline Tenure & 2.45 & 0.64 & 0.09 & 0.05 & & & & & & & & \\
\hline Learning goal ori. & 3.94 & 1.34 & 0.07 & 0.05 & -0.01 & $(0.92)$ & & & & & & \\
\hline Job autonomy & 4.65 & 1.54 & 0.04 & -0.03 & 0.02 & $0.49^{* *}$ & $(0.79)$ & & & & & \\
\hline OBSE & 4.09 & 0.81 & 0.02 & 0.04 & $0.01^{*}$ & $0.19^{* *}$ & $0.23^{* *}$ & $(0.81)$ & & & & \\
\hline Pers. inno. & 3.97 & 0.79 & 0.00 & 0.01 & -0.03 & $0.11^{*}$ & $0.17^{*}$ & $0.28^{* *}$ & $(0.85)$ & & & \\
\hline Neuroticism & 2.61 & 0.63 & $0.09^{*}$ & -0.03 & 0.00 & $-0.13^{* *}$ & $-0.27^{* *}$ & $-0.48^{* *}$ & $-0.42^{*}$ & $(0.72)$ & & \\
\hline Innovative esteem & 5.06 & 1.01 & 0.02 & 0.02 & 0.07 & $0.42^{* *}$ & $0.34^{* *}$ & $0.62^{* *}$ & $0.47^{* *}$ & $-0.51^{* *}$ & $(0.87)$ & \\
\hline Job performance & 3.47 & 1.11 & 0.01 & 0.00 & 0.05 & $0.34^{* *}$ & $0.26^{* *}$ & $0.31^{* *}$ & $0.29^{* *}$ & $-0.41^{* *}$ & $0.39^{* *}$ & $(0.80)$ \\
\hline
\end{tabular}

Source: own

Note: ${ }^{a} \mathrm{n}=304 ;$ Age: $1=20-30,2=31-40,3=41-50,4=51-60 ;$ Edu: 1 = Associate, $2=$ Bachelors, $3=$ Masters, 4 = Doctorate; Ten: 1 = 1-10, 2 = 11-20, 3 = 21-30, 4 = 31-40, 5 = 41-50;

${ }^{*} p<0.05$

${ }^{* *} p<0.01$.

\section{Tab. 2: Regression analysis for innovative esteem ${ }^{a}$}

\begin{tabular}{|c|c|c|c|}
\hline \multirow[t]{2}{*}{ Predictors } & \multicolumn{3}{|c|}{ Innovative esteem } \\
\hline & $\boldsymbol{B}$ & $R^{2}$ & $\Delta R^{2}$ \\
\hline $\begin{array}{l}\text { Step } 1 \\
\text { Control variables }\end{array}$ & & 0.02 & \\
\hline $\begin{array}{l}\text { Step } 2 \\
\text { Pers. inno. }\end{array}$ & $0.19^{* * *}$ & & \\
\hline OBSE & $0.41^{\text {t*t* }}$ & & \\
\hline LGO & $0.35^{\star * *}$ & & \\
\hline Job autonomy & $0.24^{* * * *}$ & 0.41 & $0.39^{* * *}$ \\
\hline $\begin{array}{l}\text { Step } 3 \\
\text { LGO } \times \text { Job autonomy }\end{array}$ & $0.11^{*}$ & 0.43 & $0.02^{*}$ \\
\hline
\end{tabular}

Note: ${ }^{\mathrm{a}} \mathrm{n}=304$, ${ }^{\mathrm{b}} \mathrm{Control}$ variables (Age, gender, education, tenure);

${ }^{*} \mathrm{p}<0.05$;

${ }^{* * *} p<0.001$; 
Tab. 3: Regression analysis for job performance ${ }^{a}$

\begin{tabular}{c|c|c|c|c|c|c}
\multicolumn{1}{|c|}{ Predictors } & \multicolumn{2}{|c|}{ Job performance (Time 1) } & \multicolumn{3}{c}{ Job performance (Time 2) } \\
\hline & $\boldsymbol{B}$ & $\boldsymbol{R}^{\mathbf{2}}$ & $\boldsymbol{\Delta R}^{\mathbf{2}}$ & $\boldsymbol{B}$ & $\boldsymbol{R}^{\mathbf{2}}$ & $\boldsymbol{\Delta} \boldsymbol{R}^{\mathbf{2}}$ \\
\hline $\begin{array}{c}\text { Step 1 } \\
\text { Control variables }\end{array}$ & & 0.02 & & & 0.02 & \\
\hline $\begin{array}{c}\text { Step 2 } \\
\text { Innovative esteem }\end{array}$ & $0.27^{+* *}$ & 0.15 & $0.13^{*+*}$ & $0.26^{*+*}$ & 0.11 & $0.09^{* * *}$ \\
\hline
\end{tabular}

Source: own

Note: ${ }^{a} \mathrm{n}=304,{ }^{\mathrm{b}} \mathrm{Control}$ variables (Age, gender, education, tenure);

${ }^{* * *} p<0.001$.

was significant $(F(6,297)=15.80, p<0.001)$, whereas the model was also significant with the addition of interaction term $(F(7,296)=14.23$, $p<0.001)$. Tab. 2 indicates that the interaction between job autonomy and learning goal orientation accounted for significantly more variance than just job autonomy and learning goal orientation by themselves $\left(R^{2}\right.$ change $=0.02$, $p<0.05)$ indicating that there is potentially significant moderation between job autonomy and learning goal orientation on innovative esteem. The ordinal interaction plot (see Fig. 1) demonstrates that the slope between innovative esteem and learning goal orientation increases for higher job autonomy values.
H6 was tested by using Pearson productmoment correlation and hierarchical regression analysis. As mentioned in correlation matrix the positive correlation between innovative esteem and employee job performance supports the hypothesis $(r=0.39, p<0.01)$. To test $H 6$, hierarchical regression analysis was performed on data collected on Time 1 and Time 2. In first step, control variables and employee job performance were entered. In step 2, innovative esteem was entered into the model. The results of the regression analysis presented in Tab. 3 indicate that innovative esteem $\left(\beta t_{1}=0.27\right.$, $\left.p<0.001 ; \beta t_{2}=0.26, p<0.001\right)$ is significant predictor of job performance, hence, the findings

\section{Fig. 1: Interaction between job autonomy and learning goal orientation on innovative esteem}

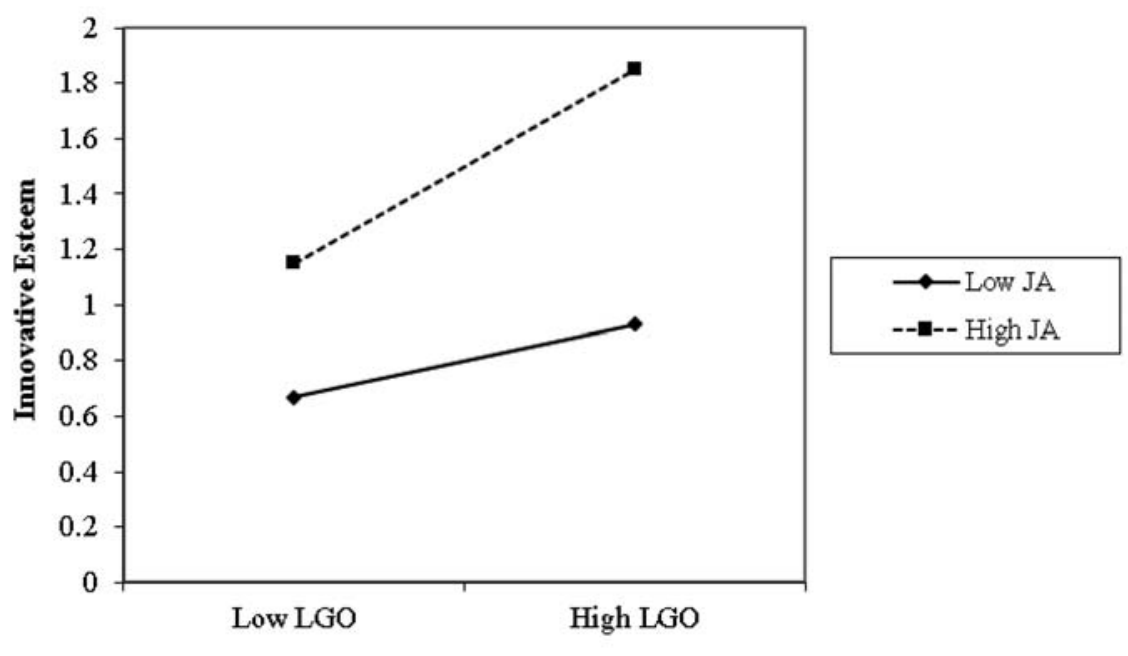


provided well support to $H 6$. Besides that, total estimated variance explained by the model for $t_{1}$ was $15 \%$, with the block of innovative esteem explaining $13 \%$ of the variance, and for $t_{2}$, total estimated variance explained by the model was $11 \%$, with the block of innovative esteem explaining $9 \%$ of the variance. Researcher believes that these results reasonably provide evidence of predictive validity.

\section{Discussion}

This study endeavours to answer the question "why innovative people are more likely to reflect high self-esteem" by proposing and validating a new innovativeness specific construct confined within self-concept paradigm. Applying construct validity theory, a nomological network is developed which successfully generated the evidence of construct validity for innovative esteem. Trochim (2016) cited that nomological network not only provides implicit definition of psychological constructs but also serves to provide evidence of construct validity which relies on agreement between nomonet and empirical data. Present study provides a set of four antecedents which were theoretically linked with innovative esteem. These relationships could pave the way in setting the directions to further explore the construct. In addition, person-context interaction theory has also been tested successfully. The test provides an evidence that job autonomy (contextual factor) moderates the relationship between learning goal orientation (personal factor) and innovative esteem. This proves the assertion that personal and contextual factors interact with each other to support innovativeness within individuals in organizational settings (Oldham \& Cumings, 1996). Further, this study also sets few construct related properties for innovative esteem. The researcher believes that innovative esteem should be confined within self-concept paradigm, and should be domain specific and performance-based construct.

This research correlates the innovative esteem with employee job performance by considering it as independent index to get an evidence of predictive validity, i.e. criterion related validity. Innovative esteem is found to be significantly and positively correlated to employee job performance. The study further applied regression analysis to strengthen the finding, and found that innovative esteem significantly predicted employee job performance. To establish evidence of stability of innovative esteem over time, researcher collected data for employee job performance along with innovative esteem again after one year, and found that innovative esteem again significantly predicted employee job performance.

\section{Implications}

Introduction to innovative esteem is likely to increase the understanding of Rogers' diffusion innovation theory. The theory explicates diffusion as a process having four basic elements, i.e. an innovation, communication channels, time period, and social system. Rogers (2003) states that "innovation is an idea, practice, or object that is perceived as new by an individual or other unit of adoption" (p. 11). No doubt that Rogers' concept of innovation is dependent on individuals. This study deems that individuals high in innovative esteem could better produce and implement their innovative ideas within reasonable time frame. Rogers also highlighted an important research question addressed by contemporary diffusion researchers, i.e. "how earlier adopters differ from the later adopters of an innovation?" According to Rogers' individual innovativeness theory (2003), there are five categories of adopters of an innovation, i.e. innovators, early adopters, early majority, late majority, and laggards. The researcher reasonably believes that among five categories of adopters "innovators" and "early adopters" should be high in innovative esteem. The rationale behind this proposition is that Rogers (2003) stated that early adopters make sagacious innovative decisions to earn self-esteem and to maintain a central position in their milieu.

If further research finds that innovative esteem contributes to practice, then managers can focus on innovative esteem of employees along with other dispositional factors to enhance innovative outcomes. Anwar (2017) suggested that tasks requiring scientific innovation and creativity could better be performed by employees high in creative self-efficacy. Present study proposes that innovative works can best be performed by employees high in innovative esteem which could be further confirmed empirically.

\section{Limitations and Future Directions}

Although time lagged design was adopted to establish an evidence of stability of innovative 
esteem over time in study sample, it has several disadvantages as well. The study took substantial amount of time to collect all the data before the patterns can even start to be made. In addition, researchers have no control and cannot determine what happens between multiple time points. Respondents might change their qualitative responses over time according to their observational and behavioural adjustments. Therefore, the reliability of data could be compromised. Such studies also experience panel attrition due to the possibility that some study subjects would no longer available due to job rotations, refusals, incapacity or death, national/international trainings, etc. This cuts down the useful data and loses important insights. Comparatively, cross-sectional studies are more affordable and final observations can be reached more quickly. Conducting time lagged study incurs more time, efforts and cost which could be considered as a major disadvantage.

Because the employees of hi-tech and R\&D organizations were conveniently selected as study sample, the study may have generalisation issues to other sectors. Other sectors such as manufacturing businesses, financial institutions, educational institutes etc, should be explored to test impact of individuals' innovative esteem on their performance outcomes. Applying random sampling techniques could further clarify the results of this study.

Future research should explore the relationship among other contextual (e.g. organizational climate, supportive leadership, transformational leadership) and personal factors (e.g. individual problem-solving style, entrepreneur orientation, social networking skills) influencing innovative esteem of employees in corporate/scientific setting. It is also suggested that relationship between innovative esteem with other popular organizational creativity related constructs such as creative self-efficacy, core self-evaluation, creative personality, and selfevaluated creativity could also be explored.

Acknowledgement: The author is thankful to organizations he is also affiliated with, i.e. Scholars Index, USA, and The Methodologists, Pakistan for providing valuable support to conduct this study.

\section{References}

Amabile, T. M., Conti, R., Coon, H., Lazenby, J., \& Herron, M. (1996). Assessing the work environment for creativity. Academy of Management Journal, 39(5), 1154-1184. https://doi.org/10.5465/256995

Anwar, C. M., Maludin, N. B., \& Chong, Y. L. (2020). Employees' evaluations about their innovative capabilities: A concept to achieve enhanced innovative performance. International Journal of Innovation Creativity and Change, 10(10), 832-854.

Anwar, M. (2015). Data health assurance in behavioural and social sciences research. European Online Journal for Natural \& Social Sciences, 4(4), 725-736.

Anwar, M. (2017). Linkages between personality and knowledge sharing behaviour: Mediating role of affective states. E\&M Economics and Management, 20(2), 102-115. https://doi.org/10.15240/tul/001/2017-2-008

Bateman, T. S., \& Grant, M. (1999). Proactive behaviour: Meaning, impact, recommendations. Business Horizons, 42(3), 63-70. https://doi. org/10.1016/S0007-6813(99)80023-8

Button, S. B., Mathieu, J. E., \& Zajac, D. M. (1996). Goal orientation in organizational research: A conceptual and empirical foundation. Organizational Behaviour and Human Decision Processes, 67(1), 26-48. https://doi.org/10.1006/obhd.1996.0063

Coopersmith, S. (1967). The antecedents of self-esteem. San Francisco, CA: W. H. Freeman \& Co.

Cronbach, L. J., \& Meehl, P. E. (1955). Construct validity in psychological tests. Psychological Bulletin, 52(4), 281-302. https://doi.org/10.1037/h0040957

Deci, E. L., \& Ryan, R. M. (2000). Selfdetermination theory and the facilitation of intrinsic motivation, social development, and well-being. American Psychologist, 55(1), 68-78. https://doi.org/10.1037/0003-066X.55.1.68

Di Domenico, S.I., \& Fournier, M. A. (2017) Esteem Needs. In V. Zeigler-Hill, \& T. Shackelford (Eds.), Encyclopedia of Personality and Individual Differences. Cham: Springer.

Dweck, C. S., \& Leggett, E. L. (1988). A social-cognitive approach to motivation and personality. Psychological Review, 95(2), 256273. https://doi.org/10.1037/0033-295X.95.2.256

Farid, H., Hakimian, F., \& Ismail, N. M. (2017). How Malaysian managers persuade employees' innovative behaviour? International Journal of Management and Enterprise Development, 16(4), 291-307. https://doi. org/10.1504/IJMED.2017.086904 
Ford, C. M. (1996). A theory of individual creativeaction in multiple social domains. Academy of Management Review, 21(4), 1112-1142. https://doi.org/10.5465/amr.1996.9704071865

Gardner, D. G., \& Pierce, J. L. (2015). Organization-based self-esteem in work teams. Group Processes and Intergroup Relations, 19(3), 394-408. https://doi. org/10.1177/1368430215590491

Goldsmith, R. E., \& Matherly, T. A. (1987). Adaption-innovation and self-esteem. Journal of Social Psychology, 127(3), 351-352. https://doi.org/10.1080/00224545.1987.9713704

Gosling, S. D., Rentfrow, P. J., \& Swann, W. B. (2003). A very brief measure of the bigfive personality domains. Journal of Research in Personality, 37(6), 504-528. https://doi. org/10.1016/S0092-6566(03)00046-1

Harris, M. A., Wetzel, E., Robins, R. W., Donnellan, M. B., \& Trzesniewski, K. H. (2018). The development of global and domain selfesteem from ages 10 to 16 for Mexican-origin youth. International Journal of Behavioral Development, 42(1), 4-16. https://doi. org/10.1177/0165025416679744

Heilman, M. E., Block, C. J., \& Lucas, J. A. (1992). Presumed incompetent? Stigmatization and affirmative action efforts. Journal of Applied Psychology, 77(4), 536-544. https://doi. org/10.1037/0021-9010.77.4.536

Hinkin, T. R., Tracey, J. B., \& Enz, C. A. (1997). Scale construction: Developing reliable and valid measurement instruments. Journal of Hospitality and Tourism Research, 21(1), 100-120. https://doi. org/10.1177/109634809702100108

Hornung. S., \& Rousseau. D. M. (2007). Active on the job proactive in change: How autonomy at work contributes to employee support for organizational change. The Journal of Behavioural Science, 43(4), 401-426. https://doi.org/10.1177/0021886307307555

Hurt, H. T., Joseph, K., \& Cook, C. D. (1977). Scales for the measurement of innovativeness. Human Communication Research, 4(1), 58-65. https://doi.org/10.1111/j.1468-2958.1977. tb00597.x

Idaszak, J. R., \& Drasgow, E. (1987). A revision of the Job Diagnostic Survey: Elimination of a measurement artifact. Journal of Applied Psychology, 72(1), 69-74. https://doi.org/10.1037/0021-9010.72.1.69

Judge, T. A., Erez, A., \& Bono, J. E. (1998). The power of being positive: The relationship between positive self-concept and job performance. Human Performance, 11(2-3), 167-187. https://doi.org/10.1207/ s15327043hup1102\&3_4

Judge, T. A., \& Bono, J. E. (2001). Relationship of core self-evaluations traits self-esteem, generalized self-efficacy, locus of control, and emotional stability - with job satisfaction and job performance: A meta analysis. Journal of Applied Psychology, 86(1), 80-92. https://doi.org/10.1037/00219010.86.1.80

Kakkar, H., Tangirala, S., Srivastava, N. K., \& Kamdar, D. (2016). The dispositional antecedents of promotive and prohibitive voice. Journal of Applied Psychology, 101(9), 13421351. https://doi.org/10.1037/apl0000130

Keller, R. T. (2012). Predicting the performance and innovativeness of scientists and engineers. Journal of Applied Psychology, 97(1), 225-233. https://doi.org/10.1037/a0025332

Kerr, S. P., Kerr, W. R., \& Xu, T. (2018). Personality traits of entrepreneurs: A review of recent literature. Foundations and Trends in Entrepreneurship, 14(3), 279-356. https://doi. org/10.1561/0300000080

Koltko-Rivera, M. E. (2006). Rediscovering the later version of Maslow's hierarchy of needs: Self-transcendence and opportunities for theory, research, and unification. Review of General Psychology, 10(4), 302-317. https://doi.org/10.1037/1089-2680.10.4.302

Krause, A. E., North, A. C., \& Davidson, J. W. (2019). Using self-determination theory to examine musical participation and well-being. Frontiers in Psychology, 10, 405. https://doi. org/10.3389/fpsyg.2019.00405

Kunst, E. M., van Woerkom, M., \& Poell, R. F. (2018). Teachers' goal orientation profiles and participation in professional development activities. Vocations and Learning, 11(1), 91-111. https://doi.org/10.1007/s12186-017-9182-y

Leavitt, C., \& Walton, J. (1975). Development of a scale for innovativeness. Advances in Consumer Research, 2(1), 545-554.

Lin, Z., \& Filieri, R. (2015). Airline passengers' continuance intention towards online check-in services: The role of personal innovativeness and subjective knowledge. Transportation research. Part E. Logistics and Transportation Review, 81, 158-168. https://doi.org/10.1016/j.tre.2015.07.001

Madsen, S. R., \& Wilson, I. K. (2012). Humanistic theory of learning: Maslow. In N. 
M. Seel (Ed.), Encyclopedia of the Sciences of Learning. Boston, MA: Springer.

Maden, D., \& Koker, N. E. (2013). An empirical research on consumer innovativeness in relation with hedonic consumption, social identity and self-esteem. Journal of Educational and Social Research, 3(7), 569-578. https://doi.org/10.5901/jesr.2013.v3n7p569

Maslow, A. H. (1943). A theory of human motivation. Psychological Review, 50(4), 370-396. https://doi.org/10.1037/h0054346

Mason, L. J. (2001). Retaining key personnel. Plus top 10 retention tips. Stress Education Centre. Retrieved from http://www. dstress.com

McCormick, B. W., Guay, R. P., Colbert, A. E., \& Stewart, G. L. (2019). Proactive personality and proactive behaviour: Perspectives on person-situation interactions. Journal of Occupational and Organizational Psychology, 92(1), 30-51. https://doi.org/10.1111/joop.12234

Mohajan, H. K. (2017). Two criteria for good measurements in research: Validity and reliability. Annals of Spiru Haret University, Economic Series, 17(4), 59-82. https://doi. org/10.26458/1746

Mosley, E., \& Laborde, S. (2016). Performing under Pressure. Performance Psychology, 291-314. https://doi.org/10.1016/ b978-0-12-803377-7.00018-1

Munton, A. G., \& West, M. A. (1995). Innovations and personal change: Patterns of adjustment to relocation. Journal of Organizational Behaviour, 16(4), 363-375. https://doi.org/10.1002/job.4030160407

Neil, A. P. (2015). Dyslexia and mental health: Helping people identify destructive behaviours and find positive ways to cope. London: Jessica Kingsley.

Nicholls, J. G., \& Miller, A. T. (1983). The Differentiation of the Concepts of Difficulty and Ability. Child Development, 54(4), 951-959. https://doi.org/10.2307/1129899

Noordzij, G., Hooft, E. A., Mierlo, H., Dam, A., \& Born, M. P. (2013). The effects of a learninggoal orientation training on self-regulation: A field experiment among unemployed job seekers. Personnel Psychology, 66(3), 723-755. https://doi.org/10.1111/peps.12011

Oldham, R., \& Cummings, A. (1996). Employee creativity: Personal and contextual factors at work. Academy of Management Journal, 39(3), 607-634. https://doi. org/10.5465/256657
Onetti, W., Fernández-García, J. C., \& Castillo-Rodríguez, A. (2019). Transition to middle school: Self-concept changes. PLoS ONE, 14(2), e0212640. https://doi.org/10.1371/ journal.pone.0212640

Pagaduan-Apostol, E. S. (2017). Assertiveness, self-esteem and academic performance in speech and oral communication of Filipino junior secondary teacher education students. Asia Pacific Journal of Multidisciplinary Research, 5(2), 36-42.

Pierce, J. L., Gardner, D. G., Cummings, L. L., \& Dunham, R. B. (1989). Organizationbased self-esteem: Construct definition measurement and validation. Academy of Management Journal, 32(3), 622-648. https://doi.org/10.5465/256437

Porath, C. L., \& Bateman, T. S. (2006). Self-regulation: From goal orientation to job performance. Journal of Applied Psychology, 91(1), 185-192. https://doi.org/10.1037/00219010.91.1.185

Pourhanifeh, G. H., \& Mazdeh, M. M. (2016). Identifying the critical success factors of organization with Analytic Hierarchy Process approach (case study - Iran Argham Company). Problems and Perspectives in Management, 14(4), 54-60. http://dx.doi.org/10.21511/ ppm.14(4).2016.06

Riaz, S., Xu, Y., \& Hussain, S. (2018). Understanding employee innovative behaviour and thriving at work: A Chinese perspective. Administrative Sciences, 8(3), 46-57. https://doi.org/10.3390/admsci8030046

Rosenberg, M. (1965). Society and the adolescent self-image. New Jersey, NJ: Princeton University Press.

Rosenberg, M., Carmi, S., Carrie, S., \& Florence, R. (1995). Global self-esteem and specific self-esteem: Different concepts, different outcomes. American Sociological Review, 60(1), 141-56. https://doi.org/10.2307/2096350

Rogers, E. M. (2003). Diffusion of innovations (5th ed.). New York, NY: Free Press.

Sipe, L. J. (2018). Connect, refresh, and energize: Enabling organizational innovation capacities through self-determination theory. Advances in Developing Human Resources, 20(2), 241-253. https://doi. org/10.1177/1523422318756637

Sternberg, R. J., \& O'Hara, L. A. (1999). Creativity and intelligence. In R. J. Sternberg (Ed.), Handbook of creativity (pp. 251-272). Cambridge: Cambridge University Press. 
Trochim, W. M. K. (2016). Research methods: The essential knowledge base. Boston, MA: Cengage Learning.

VandeWalle, D. (1993). Feedback seeking behaviour: A goal orientation model. Paper presented at Academy of Management National Meeting, Atlanta, GA.

VandeWalle, D. (1997). Development and validation of a work domain goal orientation instrument. Educational and Psychological Measurement, 57(6), 995-1015. https://doi. org/10.1177/0013164497057006009

Zhang, J., Ji, M., Anwar, C., Li, Q., \& Fu, G. (2018). Cross-level impact of team goal orientation and individual goal orientation on individual creativity. Journal of Management and Organization, 1-23. https://doi.org/10.1017/ jmo.2018.6

\section{Appendix:}

\begin{tabular}{|c|c|c|c|}
\hline Tab. 1A: & \multicolumn{3}{|l|}{ Exploratory factor analysis results } \\
\hline ID & Items & Communalities & Loadings \\
\hline ID7 & $\begin{array}{l}\text { I feel better to generate new ideas instead of working on } \\
\text { others' ideas. }\end{array}$ & 0.636 & - \\
\hline ID28 & $\begin{array}{l}\text { I actively combine novel and unrelated information in } \\
\text { order to access new experiences. }\end{array}$ & 0.597 & - \\
\hline ID12 & I am satisfied with my innovative kind of nature. & 0.692 & 0.781 \\
\hline ID8 & $\begin{array}{l}\text { I feel myself elevated when people talk about my } \\
\text { organizational contributions. }\end{array}$ & 0.788 & 0.881 \\
\hline ID1 & $\begin{array}{l}\text { I feel ultimate satisfaction when people come to know } \\
\text { about my new ideas. }\end{array}$ & 0.915 & 0.948 \\
\hline ID15 & $\begin{array}{l}\text { I like to practically implement my new ideas instead of } \\
\text { dreaming only. }\end{array}$ & 0.621 & - \\
\hline ID22 & $\begin{array}{l}\text { I always try to prove my worth through my innovative } \\
\text { work performance. }\end{array}$ & 0.524 & - \\
\hline ID6 & I feel contented when my ideas transform into reality. & 0.642 & 0.791 \\
\hline ID13 & $\begin{array}{l}\text { It gives me ultimate satisfaction when I apply my new } \\
\text { ideas mechanically. }\end{array}$ & 0.608 & - \\
\hline
\end{tabular}

Tab. 2A: Anwar's Innovative esteem Scale (AIS)
\begin{tabular}{c|l} 
No. & \multicolumn{1}{c}{ Items } \\
\hline 1 & I am satisfied with my innovative kind of nature. \\
\hline 2 & I feel myself elevated when people talk about my organizational contributions. \\
\hline 3 & I feel ultimate satisfaction when people come to know about my new ideas. \\
\hline 4 & I feel contented when my ideas transform into reality. \\
\hline
\end{tabular}

Note: Authors are welcome to adopt the Anwar's Innovative esteem Scale (AIS). To use the scale, please send an email to Mahmood.Anwar@scholarsindex.com mentioning your general research idea and how Innovative esteem construct could be useful to your research. 